\title{
On social tolerance and the evolution of human normative guidance
}

\author{
Ivan Gonzalez-Cabrera ${ }^{1,2,3}$ \\ ${ }^{1}$ Australian National University \\ ${ }^{2}$ Max Planck Institute for Evolutionary Anthropology \\ ${ }^{3}$ Konrad Lorenz Institute for Evolution and Cognition Research
}

\begin{abstract}
Discussions about the evolution of human social cognition usually portray the social environment of early hominins as highly hierarchical and dominant. In this evolutionary narrative, our propensity for violence was overcome in our lineage by a key increase of our intellectual capacities. However, I will argue in this paper that we are at least equally justified in believing that our early hominin ancestors were less aggressive and hierarchical than what is claimed by those models. This view is consistent with the available comparative and paleoanthropological evidence. I will show that this alternative model not only does not support long-held views of human origins but also has important consequences for debates about the evolution of our capacity for normative guidance.
\end{abstract}

Keywords aggression, dominance, early hominins, normative guidance, Pan/Homo LCA

Reconstructions of the last common ancestor of chimpanzees ( $P$. troglodytes), bonobos $(P$. paniscus) and humans (H. sapiens) are important in understanding human origins. These discussions usually portray the Pan/Homo last common ancestor (Pan/Homo LCA hereafter) as a chimpanzee-like hominid (Dart, 1953; Lee \& DeVore, 1969; Wrangham \& Peterson, 1996; for a historical reconstruction of this debate, see also Pickering, 2013). This has long been the prevailing view in the philosophical and biological literature, and normative and moral cognition is no exception. Recent accounts of the evolution of the human capacity for normative guidance such as Kitcher (2011) rely on this approach. I will argue that since the demonic male view and evolutionary models of normative thinking based on it no longer stand up, we need an alternative explanation of this capacity that relies on a different view of human origins. The goal of this paper is to articulate such a view. 
I will argue in this paper that we are as justified in using an alternative model of early hominins, and perhaps even the Pan/Homo LCA, as we are in believing that early ancestors were chimpanzee-like. According to this model, early hominins were much more socially tolerant and less aggressive than usually assumed. I ground this claim in both the comparative evidence and the paleoanthropological record. As a result, I will argue that this model does not fit well with views such as the demonic male view (Wrangham \& Peterson, 1996) or the killer ape hypothesis (Dart, 1953). ${ }^{1}$ More important, I will show here that such a model has important consequences for philosophical debates about the origin of our capacity for normative guidance (Kitcher, 1998, 2006, 2011).

The paper is organized as follows. In section 1, I will explain the philosophical motivations behind this debate. In section 2, I will discuss the problem of reconstructing the social behavior of our early hominin ancestors. In section 3, I shall explain the specific model of these ancestors I want to propose. In section 4 and 5, I will provide evidence in favor of this model. Finally, in section 6, I will draw out the philosophical moral of this discussion for our understanding of our capacity for normative guidance.

\section{Philosophical motivation}

Philosophers have argued that the deep history of why we became moral agents is relevant to normative philosophy. For one way to understand human nature is to understand its genealogy. One primary example is the role that various origin stories of morality have played in moral philosophy (Hobbes, 1668/1994; Nietzsche, 1887/1967; Rousseau, 1755/1992; see also Korsgaard, 2010). Another example is the way in which the evolutionary genealogy of our moral faculties have become a way to vindicate (Kitcher, 2006, 2011) or debunk morality (Joyce, 2006; Ruse, 1998; Ruse \& Wilson, 1986). As a result, genealogical projects in philosophy become highly sensitive to different assumptions about our hominin baseline. Depending on these assumptions, for instance, some evolutionary narratives will become more vindicatory than others.

\footnotetext{
${ }^{1}$ Something similar can be said about the man-the-hunter hypothesis (Lee \& DeVore, 1969). For hunting and aggression are usually considered to be a package deal. However, the model of the Pan/Homo LCA I will propose in this paper does not rule out the idea that hunting played an important role in the evolution of normative guidance.
} 
According to the demonic male hypothesis (Wrangham \& Peterson, 1996) and the killer ape hypothesis (Dart, 1953), we evolved from a chimpanzee-like hominin whose basic social nature was characterized by hostile intergroup relations. Human and chimpanzee males share a capacity for violence because our common ancestor also possessed a genetic predisposition for such capacity. On this view, this predisposition not only is an important aspect of human psychology but also it substantially contributed to the evolution of our lineage by constraining the path and setting the pace of human social-cognitive adaptations. Human ancestors were distinctively aggressive, and this trait was preserved thanks to the role of war and interpersonal aggression in the evolution of our lineage. On this picture, emotional reactivity led to social groups controlled by aggressive alpha males, but the increased cognitive demands of cooperative hunting and tool-making helped us to control our aggressive tendencies. Put another way, from a cognitive point of view, human evolution can be seen as the story of the emergence of different forms of top-down control over our more disruptive and less reliable emotional nature. ${ }^{2}$ Humans are predisposed to violence and dominance, but we overcame these limitations through the steady increase of our intellectual capabilities (see also Pinker, 2011).

This picture radically changes, however, if a different ape species such as the bonobo, not the chimpanzee, turns out to be a comparatively better model of the social behavior of our last common ancestor. If the social world of our forebears was more cooperative and peaceful than depicted by the chimpanzee referential model, neither the killer ape hypothesis nor the demonic male view of our social nature would be completely right. I will argue in this paper, for instance, that, to a large extent, emotional and affective processes played a central role in the evolution of peaceful and cooperative human societies, rather than being solely a matter of emerging top-down control mechanisms.

This hypothesis has consequences for ongoing philosophical debates. For example, recently there has been a lot of interest in the connection between morality, sexual selection, and cooperation (Joyce, 2006; Kitcher, 2011; Miller, 2007). But all these theories are built on the assumption that the social organization of early hominins closely resembled the social organization of the chimpanzee. If the sexual behavior of these hominins was less characterized by high levels of intermale and intersexual aggression than in chimpanzees,

\footnotetext{
${ }^{2}$ Top-down control is understood here as the processing of sensory and affective information that is driven by more cognitive processes such as goals or intentions. Bottom-up processing is the reverse of top-down processing, i.e., the processing of sensory and affective information that depends more directly on features of the stimulus input (for a more detailed discussion, see Rauss \& Pourtois, 2013).
} 
then the conditions for sexual selection would be radically different. Similarly, cooperation in a more socially tolerant ancestor would be different from the type of cooperation we find in highly hierarchical and aggressive primate social groups - the cognitive challenges are different and so are the mechanisms required to face them.

I shall illustrate this point with Philip Kitcher's (2011) hypothesis about the evolution of our capacity for normative guidance. According to Kitcher, the origins of the ethical project cannot be understood neither in terms of biological altruism nor in terms of behavioral altruism. The social life of our primate ancestors required a capacity for "psychological altruism'-roughly, a capacity to align one's desires in response to the perceived desires of others, and not in expectation of some future benefit. In other words, Kitcher understands the emergence of human altruistic capacities as the gradual evolution of the cognitive and motivational psychological mechanisms underlying them (see also Sober \& Wilson, 1998). This presupposes a form of belief-desire psychology, for "[...] altruists are intentional agents whose effective desires are other-directed." (p. 20) In this view, psychological altruism fostered complex forms of cooperation, and vice versa, that ultimately led to the appearance of norms and the beginning of ethical practice.

Yet psychological altruism in chimpanzees is limited in scope, as it was also in early hominins. To overcome these limitations, Kitcher argues, ancestral hominin groups developed quickly after the split with our sister lineage a capacity for normative guidance, i.e., a capacity to understand and respond to commands. He then offers a vindicating genealogy of this capacity since "[a]n ability to apprehend and obey commands changed the preferences and intentions of some ancestral hominids, leading them to act in greater harmony with their fellows and thus creating a more smoothly cooperative society". (p. 74; see also Kitcher 2006, p. 172) Kitcher's genealogy of our capacity for normative guidance is vindicating because it leads to ethical progress, beginning with its ancestral role in remedying failures of altruism in our chimpanzee-like hominin ancestors:

Tens of thousands of years ago, our remote ancestors began the ethical project. They introduced socially embedded normative guidance in response to the tensions and difficulties of life together in small groups. They were equipped with dispositions to psychological altruism that enabled them to live together, but the limits of those dispositions prevented them from living together smoothly and easily. Out of their normative ventures have emerged some 
precepts we are not likely ever to abandon, so long, at least, as we make ethical progress, the vague generalizations that embody ethical truths. (p. 409)

On Kitcher's view, the ethical project is a form of social technology that has played a central role in the gradual improvement of our hominin social life. This role is a vindicating one. Certainly, his strategy might seem unconventional since progress is usually explained in terms of truth. Instead, he thinks that his genealogy of moral cognition can make sense of ethical truth and ethical knowledge based on this notion of progress - the second part of his book is devoted to this issue. Progress is just functional efficiency. For moral practices have an original function, namely to remedy the failures of altruism that lead to social conflict. This is what Kitcher calls 'pragmatic naturalism.' As Kitcher put it: "Pragmatic naturalism retains a notion of ethical truth for expository purposes, but it starts from the concept of ethical progress." (p. 210)

As any other genealogical argument, Kitcher's vindication of the ethical project is sensitive to issues about our hominin baseline. For his account of the role of normative guidance only makes sense in the context of a demonic male view. Male aggression is not a marginal feature of Kitcher's analysis since he takes chimpanzees, rather than bonobos, as the model for our hominid past (p. 59, footnote 40) and chimpanzee societies are male-dominated societies. In his view, the evolution of normative guidance was initially grounded in fear of punishment, and the actual beginnings of the ethical project are seen as a transition from a state of limited psychological altruism to one in which commands are followed out of fear. This was so because the social life of our forebears was chimpanzee-like:

Begin with chimpanzee societies in which a crude precursor of punishment is already present. Conflicts within these groups are often settled through the interventions of a dominant animal. Here rank or physical strength (or both as concomitants of each other) prevail, and a dispute is settled - not always, of course, through the infliction of pain or discomfort on the animal whose initial defection gave rise to the conflict. (p. 87)

In these social groups, the capacity to understand and obey commands was favored by natural selection because it helped us to avoid the cost of being punished by the dominant. Thus, Kitcher's view can be understood as a form of demonic male view. 
Kitcher's account of our capacity for normative guidance is important and enlightening. But his evolutionary account relies too heavily on a version of the so-called 'chimpanzee referential doctrine' (Sayers, Raghanti, \& Lovejoy, 2012), and a version of the demonic male view - the idea that dominance and male aggression were the cardinal challenges in the evolution of human sociality. His vindicating genealogy thus follows the typical narrative of this family of views in which high-level cognition plays the leading role in the expansion of the prosocial tendencies of our lineage. As we will see later, if the model of our early ancestors I will propose here is right, Kitcher's account of the emergence of normative guidance would not be quite right. To the extent that his philosophical views (e.g., his vindication of the ethical project) rely on his evolutionary genealogy, they need to be reassessed in light of the plausibility of the different models of the social behavior of early hominins.

\section{The puzzle of hominin evolution}

Evolutionary explanations of cognition require a historical and a comparative context in order to determine the hominin baseline of social-cognitive capacities. This baseline can be established through research in comparative psychology. Most of the supporting evidence for the proposed model I will present here comes, in particular, from the comparative literature between chimpanzees and bonobos. Chimpanzees and bonobos are our closest living relatives. According to current estimates, the human lineage diverged from the Pan lineage about 6 to 4.5 mya (Prüfer et al., 2012), while chimpanzees and bonobos diverged from each other more recently, about 1-2 mya. As a result, chimpanzees and bonobos are very similar in many respects, but they are also significantly different in key social and sexual behaviors.

The differences in social behavior are particularly intriguing. Chimpanzees show a clear linear dominance hierarchy among males, with male dominance over females (Goldberg \& Wrangham, 1997). They also display relatively low levels of cooperation (Hirata \& Fuwa, 2007). In contrast, hierarchical relationships among bonobos are not always clearly defined (Kanō, 1992). Female dominance is common, and it is based on female alliances against aggressive males (Vervaecke, de Vries, \& van Elsacker, 2000). Moreover, experimental evidence also suggests that bonobos are more similar to humans in the way they solve various cooperative problems (Hare, Melis, Woods, Hastings, \& Wrangham, 2007). 
Sexual and play behaviors are different as well. In bonobos, sexual interactions occur in mixed and same-sex pairings, and it is also used for conflict resolution (de Waal, 2001; de Waal \& Lanting, 1997). Play behavior is common in adult bonobos, especially among females (Palagi, 2006). In contrast, chimpanzee sexual behavior is less rich and diverse (Goodall, 1986). Sexual interaction does not typically occur in same-sex pairings, and (as in other primates) high-ranking males monopolize estrus females. Unlike bonobos, play behavior is only frequent among chimpanzee infants, and no gender bias in terms of play behavior has been found so far.

These behavioral differences are important because apes can be used as referential models, i.e., anatomical and behavioral proxies of our last common ancestor. In these models, the ethology, ecology, and cognitive skills of great apes are used to infer the traits that are most likely the ancestral condition of modern humans. These traits are either homologies (traits inherited from a common ancestor) or analogies (traits that have evolved independently due to similar selective pressures) or a combination of both. Moreover, although it is true that the recent split and stark differences between both species suggest that a wide range of social behaviors are quite plastic and evolutionarily labile, this could hardly be the whole explanation of these differences. As we will soon see, comparative studies in Pan show that neuroanatomical differences may be responsible for these behaviors, which indicates that these traits are not just a consequence of immediate differential responses to highly idiosyncratic socioecological factors. ${ }^{3}$ Thus, given the behavioral differences between chimpanzees and bonobos, it is reasonable to assume that our early hominin ancestors were in part a mosaic of traits seen in both Pan species. ${ }^{4}$

This is a puzzle for hominin evolution since chimpanzees and bonobos constitute two very different models of our last common ancestor. The differences between these models

\footnotetext{
${ }^{3}$ Evolutionary lability can lead to these neuroanatomical differences. In plasticity-first hypotheses, phenotypic plasticity can produce developmental variants that might increase fitness (Levis \& Pfennig, 2016). Selection can then refine the trait from an initial suboptimal version through genetic accommodation or even genetically assimilate the trait when environmental sensitivity is not favored (Moran, 1992; Waddington, 1953; WestEberhard, 2003). However, although the robust neuroanatomical differences between chimpanzees and bonobos might be the result of some form of genetic accommodation or assimilation, they cannot be explained merely as an immediate response to environmental change or stress.

${ }^{4}$ Of course, this does not rule out the possibility that early hominins and the Pan/Homo LCA would have been in some respects very different from both Pan species. Fossil evidence in Ar. ramidus, for instance, indicates that the Pan/Homo LCA could have possessed anatomical adaptations for bipedalism and omnivory. This evidence will be discussed in more detail in section 5 .
} 
have important consequences - e.g., the demonic male hypothesis is only plausible if the last common ancestor was more chimpanzee-like than bonobo-like. In the next sections of this paper, I will argue that our best model of the social behavior of early hominins is not only one that carries features of chimpanzees, bonobos, and probably other species, but also one that stresses the comparative similarities between bonobos and those early ancestors. This 'mosaic model', I claim, has important consequences for our understanding of the evolutionary trajectory of our distinctive prosocial tendencies.

\section{The mosaic hypothesis}

On the view I want to defend here, early hominins were a mosaic of different traits seen not only in chimpanzees but also in other primate species. So, the key problem is to determine which particular aspects should be included in the mosaic on the basis of the available evidence. I will focus, in particular, on a version of this hypothesis, i.e., the idea that bonobos are to some degree a constitutive part of that mosaic. Of course, my concern here is not whether bonobos are closer to us than chimpanzees. Nor is it which species better resembles, say, the Pan/Homo LCA. My claim is a comparative one, namely that bonobos are in some important respects a more suitable model of the social behavior of early hominins and the Pan/Homo LCA with respect to our equally distant relative, the chimpanzee.

The overall picture of this comparative model is one in which early hominin ancestors were characterized by a level of social tolerance and prosocial skills that went beyond the usual chimpanzee referential model. This is not a minor issue. For increased social tolerance and enhanced prosocial skills diminish the role of aggression and dominance in the evolution of our lineage. They make aggression and dominance less restrictive constraints on the evolutionary trajectory of the lineage when the selective pressures for increased cooperation escalated. Adaptations for tolerance and prosociality make the evolutionary trajectory toward seemingly distinctive human traits such as imitative learning (Galef, 1996, 2009; Tomasello, 2009) or collective foraging (Tomasello, Melis, Tennie, Wyman, \& Herrmann, 2012) more accessible.

The feasibility of the mosaic hypothesis and the version of this model I propose here are supported in the first place by genetic evidence. Recently, Prüfer and colleagues (2012) have completed the sequencing of the bonobo genome and have compared it to the already sequenced genome of chimpanzees and humans. They showed that about $1.6 \%$ of the human 
genome is more closely related to (i.e., more similar to homologues in) bonobos than chimpanzees while $1.7 \%$ of the human genome is more closely related to the chimpanzee than to the bonobo genome (Prüfer et al., 2012, pp. 2-3). Given the behavioral differences between chimpanzees and bonobos, they argue that, at least in principle, the last common ancestor of these three species could have possessed traits seen in both Pan species (2012, p. $527)$.

This genetic evidence not only gives prima facie motivation for the idea that the Pan/Homo LCA had some bonobo-like traits. It also suggests that bonobos can be useful referential models. The value of bonobos as models of early hominins is likely not only limited to common ancestry, though. It is also plausible that many features we see in this extant species resemble those we see in human because both species underwent similar selective regimes (see section 6 in this paper for discussion). Either way, I would like to argue that it is quite possible that our early hominin ancestors, and even perhaps the Pan/Homo LCA, were characterized by:

(i) group hunting behavior,

(ii) enhanced emotional control,

(iii) increased aversion against aggression (specially intermale and intergroup aggression),

(iv) enhanced brain connectivity for empathy (top-down and bottom-up control of aggressive impulses),

(v) increased mind reading skills,

(vi) increased cooperative and sharing tendencies,

(vii) non-linear/ill-defined hierarchy,

(viii) and non-exclusive male dominance.

Traits (ii)-(vi) are comparative features, i.e., they are traits of early hominins that are well above the hypothesized levels of a chimpanzee-like model of that ancestor. According to these features, the social life of our early ancestors was in these respects more bonobo-like than chimpanzee-like. This does not rule out, of course, that other species could be in principle a better model for these features. But for the purpose of the present argument, these comparative claims suffice. For the evolutionary trajectory would be less constrained by our aggressive and dominant tendencies, such that overcoming them would be displaced (so to speak) from the center of gravity of our evolutionary narrative. In other words, if the present 
model is on the right track, there would be sufficient reasons to be skeptical about the killer ape hypothesis or the demonic male view of the social-cognitive capacities of our early hominin ancestors.

Moreover, from a philosophical point of view, this model would lead us to reassess naturalistic arguments based on these assumptions, such as Kitcher's evolutionary narrative of the emergence of our capacity for normative guidance. For the above model would be linked to a different picture of the trajectory of hominin social evolution and the timing of the appearance of more complex forms of social cognition. As I will argue later, the fossil record supports the view that very early in our lineage, hominins were less aggressive and more tolerant than commonly assumed by chimpanzee referential models.

\section{Evidence for the model}

The features of the proposed model are closely linked to social behavior. In behavioral phylogenetics, it is possible to reconstruct an ancestor's behaviors if such behaviors are present in all of its living descendants. This argument relies on considerations of parsimony. To the extent that parsimony is a guide, group hunting would be characteristic of our last common ancestor. For recent evidence shows that this behavior is also present in the bonobo (Surbeck \& Hohmann, 2008). The same goes for some aspects of physical cognition such as tool manufacture and use (Gruber, Clay, \& Zuberbühler, 2010; Ingmanson, 1996).

Since humans also possess those behavioral traits, it is possible to infer that the Pan/Homo LCA did (i) hunt in groups. It is true that, given that traits such as tool manufacture and use are present in all great apes and also in other primate species, their presence in early hominins is a somewhat more conservative phylogenetic inference than group hunting. The set of data points is significantly smaller in that case. Nonetheless, there is evidence that by 3.4 mya hominins were using stone tools to hunt large mammals (McPherron et al., 2010), which pushes the plausibility of ape-like hunting much deeper in the hominin lineage. Therefore, it is just as likely, if not more likely, that group hunting was present in the Pan/Homo LCA as assuming that it emerged very early in our lineage and then independently in Pan.

In addition, the neural circuitry that mediates anxiety, empathy, and the inhibition of aggression in humans is better developed in bonobos than in chimpanzees. Bonobos and humans have a similar organization in the orbitofrontal cortex and a relatively smaller area 13 
(Semendeferi, Armstrong, Schleicher, Zilles, \& Van Hoesen, 1998). Differences in the organization and size of these parts of the brain influence emotional reactions and social behavior, e.g., area 13 is known to be associated with changes in emotional states and disinhibition of emotional reactions.

Bonobos and humans also possess a similar distribution of von Economo (VEN) neurons in the anterior cingulate and frontoinsular cortex (Nimchinsky et al., 1999). In humans, their hypothesized functions include self- and social awareness, self-control, and empathy (Allman et al., 2010, 2011), which would be crucial for bonobo social organization and its typically weak dominance hierarchy. They are also thought to be an important part of the circuitry responsible for rapid intuitive choice in complex social situations (Allman, Watson, Tetreault, \& Hakeem, 2005). ${ }^{5}$

Similarly, recent comparative studies have shown that two pathways, one connecting the amygdala and the anterior cingulate cortex, and another connecting the amygdala and the ventromedial prefrontal cortex, are larger in bonobos than chimpanzees (Rilling et al., 2011). The former is implicated in emotion regulation in humans while the latter enables the restraint of aggression via top-down suppression of aggressive impulses from the amygdala (Davidson, Putnam, \& Larson, 2000; Meyer-Lindenberg et al., 2006; Pezawas et al., 2005). The same pathway may also be involved in controlling aggressive impulses through a bottom-up relay of perceived distress in others to the ventromedial prefrontal cortex that inhibits anti-social behavior (Blair, 2007, 2008).

Insofar as the above neurobiological traits are examples of fine-grained similarities, then parsimony suggests that the early hominins possessed (ii) enhanced emotional control, (iii) increased aversion against aggression, and (iv) enhanced brain connectivity for empathy with respect to a hypothetical chimpanzee-like model of these ancestors. A broader look at the neurobiology of other empathic and tolerant primate species gives some additional support to this view. For callitrichid monkeys, for instance, are quite socially tolerant but their social behavior relies on somewhat different neural circuitry. They possess small brains and their empathic behavior is mediated by physiological responses that are especially geared

\footnotetext{
${ }^{5}$ As pointed out by one of the reviewers of this paper, the importance of VEN neurons can be understood more fully along with the hypothesis that developmental and degenerative diseases such as autism (Allman et al., 2005; Santos et al., 2011), frontotemporal dementia (Santillo et al., 2014; Seeley et al., 2006), and schizophrenia (Brüne et al., 2010) may be connected with its recent evolutionary history. Since all these disorders affect the social brain, these findings seem to support the idea that these neurons have acquired a specific role in mammals living in large and complex social groups (Cauda, Geminiani, \& Vercelli, 2014).
} 
to cooperative breeding (Fernandez-Duque, Valeggia, \& Mendoza, 2009). This indicates that empathy and emotion regulation are not necessarily related to an increase in gray and white matter connectivity as in bonobos and humans, which makes a hypothesis about convergent evolution less likely.

Bonobos are also more socially tolerant than chimpanzees, especially when cofeeding (Hare et al., 2007). They show a stronger stress hormone response to feeding competition (Wobber et al., 2010). They have also been described as more nervous and shy than chimpanzees (de Waal \& Lanting, 1997). As in humans, these differences in temperament are associated with enhanced social-cognitive skills. Studies with young children, for instance, show a strong connection between shyness and mindreading skills (Wellman, Lane, LaBounty, \& Olson, 2011). Similarly, bonobos outperform chimpanzees in tasks related to mindreading, while chimpanzees are more skilled at tasks requiring the use of tools and an understanding of physical causality (Herrmann, Hare, Call, \& Tomasello, 2010).

Differences in mindreading skills, however, cannot be explained solely on the basis of social tolerance. These differences are products of a particular neural system for understanding the intentional states of others. The medial prefrontal cortex and the temporoparietal junction are known to be implicated in mindreading capabilities in humans (Gallagher \& Frith, 2003; Saxe \& Kanwisher, 2003). Thus, the fact that bonobos also have increased gray matter in the dorsomedial prefrontal cortex compared with chimpanzees seems to be telling. Mindreading skills in apes are typically linked to competitive contexts (Call \& Tomasello, 2008), but there is no reason to think that food and mating competition is stronger in bonobos than chimpanzees. Thus, explaining this increased capacity in bonobos through a convergent selective gradient seems problematic.

Levels of tolerance also affect sharing behavior in Pan. Chimpanzees share food with conspecifics only under some circumstances-e.g., food transfer from mother to offspring (Ueno \& Matsuzawa, 2004) or when the food is not valuable and not monopolizable (Blurton-Jones, 1987; Gilby, 2006). However, peaceful food sharing in wild bonobos seems to contradict the usual sharing-under-pressure hypothesis (Yamamoto, 2015). Under experimental conditions, active and voluntary food sharing also seems to be present in bonobos (Hare \& Kwetuenda, 2010), even among strangers and when food is easily monopolizable (Tan \& Hare, 2013).

Moreover, recent studies suggest that selection on emotional reactivity critically shapes a species' ability to solve social problems (Hare et al., 2005; Hare \& Tomasello, 2005). This hypothesis, for instance, predicts that bonobos will cooperate more successfully 
in food-retrieval tasks than chimpanzees because tolerance levels are higher in bonobos. So, although experimentally both species have been shown to be equally successful at cooperating when food is difficult to monopolize, tests with monopolizable food have shown that bonobos are much more prone to cooperation than chimpanzees (Hare et al., 2007).

Given the differences in temperament between chimpanzees and bonobos, it is at least as plausible that early hominins possessed (v) increased mindreading skills and (vi) increased cooperative and sharing tendencies with respect to a hypothetical chimpanzee-like model of the Pan/Homo LCA as it is to adopt the standard chimpanzee referential model. This is a nonnegligible difference in social-cognitive abilities. The fact that these differences are correlated with particular neurobiological similarities between bonobos and humans also deserves attention. The chimpanzee's mindreading and cooperative capacities cannot simply be taken to represent the ones of early hominins.

Naturally, sexual behavior in all the three species has important differences. But a crucial similarity between bonobos and humans is that both species use sexual behavior in a social context. Unlike chimpanzees, female bonobos are continuously sexually active and attractive. So, in bonobos and humans, sexual intercourse can be initiated at any point, which in turn increases bonding between individuals. Bonobos with lower testosterone levels and attenuated testosterone responses engage more often in amicable relationships with unrelated females and have greater reproductive success (Surbeck, Deschner, Schubert, Weltring, \& Hohmann, 2012). Therefore, bonobo males benefit from affiliative long-term association with females (Surbeck et al., 2012), which facilitates more egalitarian and more peaceful social lives.

Similarly, hypothalamus size and amygdala size have been shown to predict social play frequency in non-human primates but not nonsocial play (Lewis \& Barton, 2006). Bonobos-females more than males-seem to use play to assess physical skills, the willingness of other individuals to invest in a relationship, and to strengthen already existing social bonds. Adult bonobos play much more frequently than chimpanzees. This asymmetry is important because it has been experimentally shown that both species use grooming and play as social currency (Schroepfer-Walker, Wobber, \& Hare, 2015). Play is a valuable social interaction and can be used to establish social preferences depending on the amount of playful interactions between individuals. Thus, play behavior could also have a crucial role in the bonobo social organization and its typically weak dominance hierarchy.

To the extent that the above neurobiological similarities are correlated with the more egalitarian social structure of bonobos, they would suggest that early hominins lived in (vii) 
less hierarchical and arguably (viii) less male-dominated social groups with respect to a hypothetical chimpanzee-like model of the Pan/Homo LCA. Explanations of the evolution of the bonobo usually argue that reduced male aggression toward females was sexually selected (Wrangham \& Peterson, 1996). But it is at least equally likely that this trait was inherited from the common ancestor, especially in light of the fact that the traditional evolutionary scenario for the split between chimpanzees and bonobos is not supported by our current knowledge about the formation of the Congo River (Takemoto, Kawamoto, \& Furuichi, 2015). ${ }^{6}$

Granted, this is not conclusive evidence for the mosaic hypothesis or the particular model I have offered in the previous section. However, even if the case for the model is not compelling enough, we have good reasons to think that the social behavior of early hominins, including the Pan/Homo LCA, was in many respects not chimpanzee-like. The chimpanzee referential model could not be anymore the default assumption.

\section{Paleoanthropological support}

Although certainly thin, the above evidence suggests that the Pan/Homo LCA was in some respects more bonobo-like than chimpanzee-like. In this section, I will argue that even if the Pan/Homo LCA was not characterized by the features ascribed in the model, we still have reasons to think that they evolved very early in our lineage. For the paleoanthropological evidence suggests that early hominins were much more socially tolerant than the chimpanzee referential doctrine actually tells us (Sayers et al., 2012).

Fossil evidence is central to whatever model of our hominin ancestry we choose. Referential models are constrained by phylogenetic inferences-after all, phylogenetic analysis can be understood as a form of referential modeling (Duda \& Zrzavý, 2013). But fossil evidence particularly restricts the scope and shape of these models. Generally speaking, referential models are either based on homology through shared descent (McGrew, 1981) or

\footnotetext{
${ }^{6}$ According to this hypothesis, the formation of the Congo River isolated an ancestral population of the common ancestor of chimpanzees and bonobos around 2 mya (Wrangham \& Peterson, 1996; Wrangham, 1993). This population did not have to compete with gorillas for resources, which allowed females to form coalitions and resist the advances of males. Since coercion was not an efficient mating strategy, sexual selection favored less aggressive males. This led to the evolution of bonobos and their distinctively low levels of aggression. However, the current geological evidence contradicts this scenario because it indicates that the present Congo River was formed much earlier, around 34 mya.
} 
analogy through convergent evolution (DeVore \& Washburn, 1963; Fernandes, 1991; Jolly, 2001; Perry et al., 2003). The above model can be considered rather neutral regarding this issue.

Paleoanthropological evidence, however, suggests that even if some aspects of the proposed model are not homologies, i.e., ancestral traits of the Pan/Homo LCA that have been retained by bonobos and humans, they might have evolved early in our lineage. This view is supported by fossil evidence from Sahelanthropus, Orrorin, and Ardipithecus, which indicates that our lineage was less aggressive and less male-dominated than assumed by the traditional chimpanzee referential model (Brunet et al., 2002; Haile-Selassie, Suwa, \& White, 2004; Pickford \& Senut, 2001; White et al., 2009).

Early hominins and the Pan/Homo LCA could also have been very different from both Pan species. Fossil evidence from Ar. ramidus, for instance, indicates that this early hominin was well-adapted to bipedality, although it retained arboreal capabilities (Lovejoy, Latimer, Suwa, Asfaw, \& White, 2009). This means a more human-like locomotion system, quite different from that seen in any extant ape. Another important difference is that $A r$. ramidus appears to be neither a ripe fruit specialist like Pan, nor a folivorous browser like Gorilla, but rather a more generalized omnivore (Suwa et al., 2009). However, the same fossil evidence also suggests that the social behavior of the Pan/Homo LCA was in many important respects more bonobo-like than chimpanzee-like and that this social behavior is likely to be an ancestral condition.

Evidence from Ardipithecus ramidus is particularly telling. The fossil record of this ancestor is rich and the completeness of some remains makes sex assessment relatively reliable (White, Lovejoy, Asfaw, Carlson, \& Suwa, 2015; White, Suwa, \& Asfaw, 1994). Dating estimates place this hominin at circa 4.4 mya, very close to the split between these two lineages, which makes this ancestor highly relevant for reconstructing the morphology and behavior of the Pan/Homo LCA.

Ar. ramidus remains reveal that this hominin was characterized by reduced canine teeth and low body size dimorphism. In basal dimensions, the canines of Ar. ramidus are approximately as large as those of female chimpanzees and male bonobos, although their crown heights are shorter; they are comparable to those of Australopithecus anamensis and Australopithecus afarensis (Suwa et al., 2009). They are also 'feminized' in shape. The size of the upper canine tooth is not only similar to that of females, but also less sharp than those of chimpanzees. 
Reduced canine teeth dimorphism is a common feature of the hominin clade. Along with Ar. ramidus, this trait is seen in Sahelanthropus (Brunet et al., 2002, p. 150), Orrorin (Senut et al., 2001), and Ar. kadabba (Haile-Selassie, 2001). Since the canine tooth is usually used as a weapon in intermale and intergroup conflicts, the less pronounced upper canine teeth suggests that early hominins, including Ar. ramidus, were characterized by relatively little intermale and intergroup aggression compared to chimpanzees.

Similarly, Ar. ramidus is also expected to have shown little sexual dimorphism in body size - comparable to that of chimpanzees or humans, as opposed to orangutans or gorillas (White et al., 2009). In higher primates, body size dimorphism is usually coupled with strong canine dimorphism. Using dimorphism to infer behavior in early hominids is usually problematic because their unique combination of minimal canine size dimorphism and intense body mass dimorphism (Plavcan \& van Schaik, 1997). But this is not the case in Ar. Ramidus. As a consequence, lack of sexual dimorphism seems to indicate that males did not compete against each other for dominance.

While intermale and intergroup aggression are frequent among chimpanzees, $A r$. ramidus possessed low levels of agonistic male-male competition (Clark \& Henneberg, 2015) - and even, perhaps, male-female codominance as in bonobos (Suwa et al., 2009, p. 57). We cannot be sure about these aspects of the social behavior of our early ancestors, but we can infer them indirectly. For early hominins do not seem to have any of the adaptations for agonistic male-male competition present in other living primates. In turn, reduced male sexual dimorphism does not seem to have an obvious survival advantage. Yet this trait could have led to a reproductive advantage through sexual selection-e.g., because bipedalism facilitated provisioning, which would have been a more efficient mating strategy (Lovejoy, 2009).

Parallel evolution does not always seem to give us the most parsimonious reconstruction of these traits. Chimpanzees are more sexually dimorphic than bonobos and humans, and australopithecines were more sexually dimorphic than both extant Pan species (Gordon, Green, \& Richmond, 2008; Van Arsdale \& Wolpoff, 2013)—which is true in terms of body size but not canine size (Leutenegger \& Shell, 1987; McHenry, 1992; Plavcan \& van Schaik, 1992). Therefore, to the extent that australopithecines are direct ancestors of modern humans (and not a paraphyletic sister lineage, which they may be), this loss of sexual 
dimorphism must have not only occurred twice independently, in Pan and in Homo, but also in Ar. ramidus. ${ }^{7}$

Another option would be to suggest that low sexual dimorphism is, in fact, the ancestral condition, with a pattern of increasing dimorphism in australopithecines and chimpanzees. Australopithecines would be a paraphyletic sister lineage (an alternative pointed out to me by Kim Shaw-Williams, personal communication), or not as sexually dimorphic as it has often been claimed (Reno, McCollum, Meindl, \& Lovejoy, 2010; Reno, Meindl, McCollum, \& Lovejoy, 2003). In this way, the evolutionary trajectory of the human lineage could be explained without postulating so many evolutionary reversals, or by invoking less drastic shifts. However, this would challenge the current picture of Australopithecus as a very aggressive, highly sexually dimorphic genus, or even its place as direct human ancestor - a hypothesis that, nonetheless, would be worth exploring (see figure $1)$.

\footnotetext{
${ }^{7}$ A similar problem occurs with diet. Ar. ramidus and modern humans are omnivorous, but australopithecines were largely frugivorous, similar to extant Pan. They lack the particular dental adaptations that are characteristic of omnivores. This means that these adaptations would have disappeared in australopithecines to reappear later in the human lineage and then disappear again in Pan.
} 


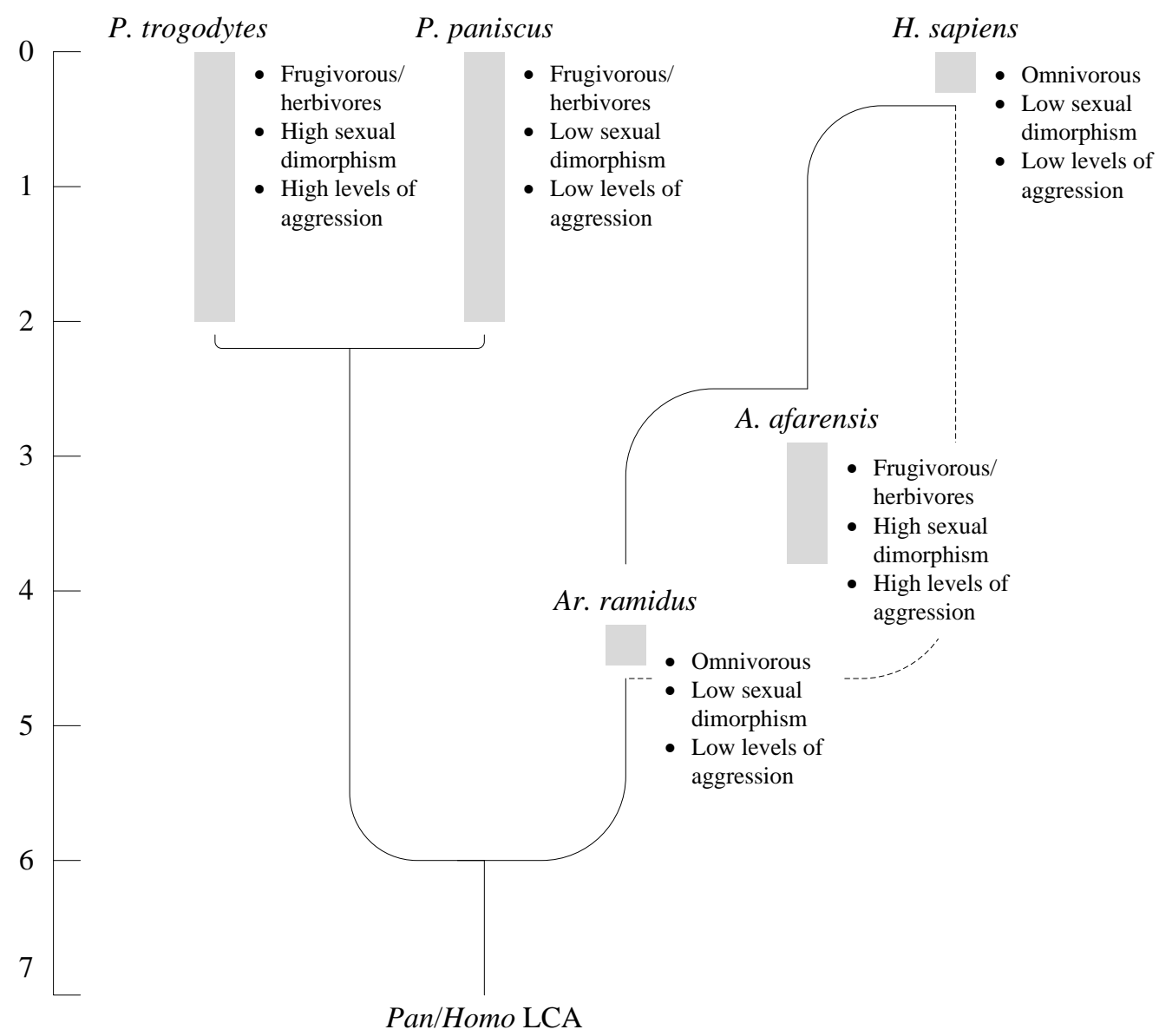

Figure 1. Diagram of two evolutionary arrangements of five hominid species. According to one view (solid line), Ar. ramidus and A. afarensis are direct ancestors of humans ( $H$. sapiens). But Ar. ramidus, bonobos (P. paniscus), and humans are characterized by low sexual dimorphism and low levels of intermale and intergroup aggression while A. afarensis and chimpanzees ( $P$. troglodytes) show increased levels of sexual dimorphism and aggression. On top of that, Ar. ramidus and humans are characterized by an omnivorous diet and a similar dentition, although A. afarensis and Pan have specialized masticatory apparatus. A more parsimonious reconstruction (dashed line) would be then to consider A. afarensis not as the direct ancestors of modern humans, but rather as part of a paraphyletic sister lineage.

It is not clear whether body size dimorphism in australopithecines is a consequence of male-male competition since their canines have a variety of features inconsistent with their use as a weapon (Greenfield, 1992). There are multiple reasons that could potentially explain the increase in body size dimorphism in australopithecines, e.g., reduction in female body size (Leigh \& Shea, 1995), predator defense (Clutton-Brock, Harvey, \& Rudder, 1977), or the Rench's rule (see Fairbairn, 1997).

Although there is no necessary link between the specific features ascribed by the model and the paleoanthropological evidence, the common theme of reduced (or controlled) 
aggression in early hominins stands. Even if the Pan/Homo LCA was very different from the proposed model, a decrease in these aggressive tendencies seems to have occurred very early in our lineage. Notably, for instance, increased levels of social tolerance have been associated with early heterochronic changes in craniofacial growth. So, it might well be the case that in Ar. ramidus the energetic demands of craniofacial growth were redirected to provisioning (Clark \& Henneberg, 2015).

\section{Philosophical consequences}

The model I have defended in this paper has important philosophical consequences for descriptive theories of ethics. For it gives us a different picture of the evolution and nature of our capacity for normative guidance (Kitcher, 1998, 2006, 2011), i.e., our capacity to grasp norms and to make normative judgments.

In section 1, I suggested that Kitcher's account of the emergence of the capacity for normative guidance is a particular form of the demonic male view. Similar to this view, Kitcher's evolutionary scenario relies on a chimpanzee-like social environment where dominance and aggression are the key driving forces behind human evolution. On Kitcher's account, dominant alpha males punish anyone who disrupts the established social order, and this makes normative guidance, at least initially, psychologically grounded in fear. In addition, as in the demonic male view, the evolution of our capacity for normative guidance is in part the story of the gradual expansion of top-down mechanisms of control (in the form of some sensitivity to commands) over our less reliable emotional nature. If an agent is able to understand the normative structure of its chimpanzee-like social environment, that agent will be able to avoid the costs imposed by aggressive alpha males. The motivational force to obey these commands comes for free in this case since they help the agent to avoid situations in which the anticipated consequences are feared or disliked.

The above model, then, bears important consequences for Kitcher's view of normative guidance and its function. For, according to him, normative guidance has to be more explicit, more a matter of offline cognition. But the model of early hominins I presented in section 3 strongly suggests that neither the demonic male view nor Kitcher's (2011) account of our capacity for normative guidance are plausible. On this model, the social world of our last common ancestor is not male-dominated (viii), their social organization is less hierarchical (vii) and social cohesion is less regulated by aggression and fear of punishment 
(vi). On the contrary, this ancestor is characterized by its enhanced emotional control (ii), increased aversion against aggression (iii), empathy and positive emotions (iv), and enhanced perspective taking capacities (v). If this is correct, normative guidance would not have been selected for avoiding punishment by very aggressive and authoritative alpha males. Kitcher's vindicating genealogy becomes murky. The tendencies of some individuals to monopolize resources and to impose social order through aggression would have been largely regulated in our lineage through more bottom-up affective processes. No sensitivity to commands is required. No norms are invoked. Another explanation would be necessary.

Kitcher's evolutionary account of normative guidance is not the only available explanation. It is also not the best. I think a better explanation of the shift toward normative guidance could be framed in terms of shared intentionality (Tomasello \& Carpenter, 2007). Shared intentionality seems to account for much of the distinctive features of human psychology. It has been argued, for instance, that such capacity is responsible for the appearance of joint attention, cooperative communication, imitative learning, and teaching, which are at the basis of cultural learning and the social norms and traditions we see in human culture (Tomasello, 2014). Although joint activities and behavioral traditions are common among great apes, humans substantially differ from other apes in their underlying psychological mechanisms. Chimpanzees and bonobos can attribute some psychological states such as perceptions and goals to others (Tomasello, Call, \& Hare, 2003), but they are neither intrinsically motivated to share those psychological states nor are able to represent these mental states in a joint, collective fashion (Call, 2009).

Primates do form social expectations but they lack the capacity to form normative ones (von Rohr, Burkart, \& van Schaik, 2011). Normative expectations depend for their emergence and maintenance on shared acceptance and commitment. Joint goals, for instance, are normatively binding mental states of the form "We intend to do $x$ ". If someone unexpectedly abandons the joint activities that these states bring about, other group members may demand an explanation and censure that partner (Warneken, Chen, \& Tomasello, 2006; Warneken, Gräfenhain, \& Tomasello, 2012; Warneken, Hare, Melis, Hanus, \& Tomasello, 2007). Thus, abandoning the joint activity naturally entails a risk of reprisal (Gilbert, 1989). Similarly, it has been argued that shared intentionality also has straightforward consequences for moral cognition (Tomasello, 2015) since, as Christine Korsgaard has nicely put it: "The primal scene of morality [...] is not one in which I do something to you or you do something to me, but one in which we do something together" (1993, p. 25). 
Given that much of the empirical work on this psychological phenomenon comes from the comparative literature, the theory on shared intentionality offers a helpful framework to put normative guidance within an evolutionary context. This capacity, for instance, is thought to be closely linked to the selective pressures resulting from cooperative activities such as cooperative breeding and collaborative foraging. The former is often considered a previous step for the full emergence of shared intentionality (Hawkes, 2012, 2014) because, although cooperative breeding leads to greater prosocial skills, it does not entail in itself higher cognition (Burkart et al., 2014). For this reason, it has been argued that the selective pressures of collaborative foraging, which are more cognitively demanding in terms of coordination, would explain the emergence of the type of complex cognition underlying shared intentionality, starting with Homo erectus and continuing with Homo heidelbergensis (Tomasello et al., 2012).

Since it is only with the emergence of collaborative foraging that we can fully explain the emergence of shared intentionality, it would be only until then that we could expect social norms to emerge-i.e., understanding them as mutually known expectations bearing social force and enforced by third parties. The fact that the increase in the gradient of human cooperation would be partially explained by the role of normative thinking in facilitating coordination would explain why some (Sterelny, 2012; Sterelny \& Fraser, unpublished) only see a partial or incomplete vindication in this type of genealogies since many norms could have evolved to fix coordination problems in situations where multiple equilibria are possible.

In sum, one idea for further exploration would be to think of our capacity for normative guidance as having been selected for to avoid disappointing a relationship partner's expectations in a more tolerant social environment when hominins became more interdependent foragers (Tomasello et al., 2012). Norms would be conceived as shared expectations about how individuals ought to behave in a given situation, i.e., they would be represented as joint intentional states. These expectations were necessary to carry out tasks that required complex coordination such as collaborative foraging and more so to build the kind of collective cultural institutions that are the distinctive feature of behaviorally modern humans.

\section{References}


Allman, J. M., Tetreault, N. A., Hakeem, A. Y., Manaye, K. F., Semendeferi, K., Erwin, J. M., . . . Hof, P. R. (2010). The von Economo neurons in frontoinsular and anterior cingulate cortex in great apes and humans. Brain Structure \& Function, 214(5-6), 495-517.

Allman, J. M., Tetreault, N. A., Hakeem, A. Y., Manaye, K. F., Semendeferi, K., Erwin, J. M., . . Hof, P. R. (2011). The von Economo neurons in the frontoinsular and anterior cingulate cortex. New Perspectives on Neurobehavioral Evolution, 1225, 59-71.

Allman, J. M., Watson, K. K., Tetreault, N. A., \& Hakeem, A. Y. (2005). Intuition and autism: a possible role for Von Economo neurons. Trends in Cognitive Sciences, 9(8), 367-373.

Blair, R. J. R. (2007). The amygdala and ventromedial prefrontal cortex in morality and psychopathy. Trends in Cognitive Sciences, 11(9), 387-392.

Blair, R. J. R. (2008). The amygdala and ventromedial prefrontal cortex: functional contributions and dysfunction in psychopathy. Philosophical Transactions of the Royal Society B., 363(1503), 2557-2565.

Blurton-Jones, N. G. (1987). Tolerated Theft, Suggestions About the Ecology and Evolution of Sharing, Hoarding and Scrounging. Social Science Information Sur Les Sciences Sociales, 26(1), 31-54.

Brüne, M., Schöbel, A., Karau, R., Benali, A., Faustmann, P. M., Juckel, G., \& PetraschParwez, E. (2010). Von Economo neuron density in the anterior cingulate cortex is reduced in early onset schizophrenia. Acta neuropathologica, 119(6), 771-778.

Brunet, M., Guy, F., Pilbeam, D., Mackaye, H. T., Likius, A., Ahounta, D., . . Zollikofer, C. (2002). A new hominid from the Upper Miocene of Chad, Central Africa. Nature, 418(6894), 145-151.

Burkart, J. M., Allon, O., Amici, F., Fichtel, C., Finkenwirth, C., Heschl, A., . . van Schaik, C. P. (2014). The evolutionary origin of human hyper-cooperation. Nature Communications, 5 .

Call, J. (2009). Contrasting the Social Cognition of Humans and Nonhuman Apes: The Shared Intentionality Hypothesis. Topics in Cognitive Science, 1(2), 368-379.

Call, J., \& Tomasello, M. (2008). Does the chimpanzee have a theory of mind? 30 years later. Trends in Cognitive Sciences, 12(5), 187-192.

Cauda, F., Geminiani, G. C., \& Vercelli, A. (2014). Evolutionary appearance of Von Economo's Neurons in the mammalian cerebral cortex. Frontiers in Human Neuroscience, 8. 
Clark, G., \& Henneberg, M. (2015). The life history of Ardipithecus ramidus: a heterochronic model of sexual and social maturation. Anthropological Review, 78(2), 109-132.

Clutton-Brock, T. H., Harvey, P. H., \& Rudder, B. (1977). Sexual Dimorphism, Socionomic Sex-Ratio and Body-Weight in Primates. Nature, 269(5631), 797-800.

Dart, R. (1953). The Predatory Transition from Ape to Man. International Anthropological and Linguistic Review, 1, 201-217.

Davidson, R. J., Putnam, K. M., \& Larson, C. L. (2000). Dysfunction in the neural circuitry of emotion regulation: A possible prelude to violence. Science, 289(5479), 591-594.

de Waal, F. B. M. (2001). Apes from Venus: Bonobos and Human Social Evolution. In F. B. M. d. Waal (Ed.), Tree of origin: what primate behavior can tell us about human social evolution (pp. 39-68). Cambridge, MA/London: Harvard University Press.

de Waal, F. B. M., \& Lanting, F. (1997). Bonobo: the forgotten ape. Berkeley, CA: University of California Press.

DeVore, I., \& Washburn, S. L. (1963). Baboon ecology and human evolution. In F. C. Howell \& F. o. Bourlière (Eds.), African ecology and human evolution (pp. 335-367). Chicago: Aldine Pub. Co.

Duda, P., \& Zrzavý, J. (2013). Evolution of life history and behavior in Hominidae: Towards phylogenetic reconstruction of the chimpanzee-human last common ancestor. Journal of Human Evolution, 65(4), 424-446.

Fairbairn, D. J. (1997). Allometry for sexual size dimorphism: Pattern and process in the coevolution of body size in males and females. Annual Review of Ecology and Systematics, 28, 659-687.

Fernandes, M. E. B. (1991). Tool Use and Predation of Oysters (Crassostrea-Rhizophorae) by the Tufted Capuchin, Cebus-Apella-Apella, in Brackish Water Mangrove Swamp. Primates, 32(4), 529-531.

Fernandez-Duque, E., Valeggia, C. R., \& Mendoza, S. P. (2009). The Biology of Paternal Care in Human and Nonhuman Primates. Annual Review of Anthropology, 38, 115130.

Galef, B. G. (1996). Food selection: Problems in understanding how we choose foods to eat. Neuroscience and Biobehavioral Reviews, 20(1), 67-73.

Galef, B. G. (2009). Culture in animals? In K. N. Laland \& B. G. Galef (Eds.), The question of animal culture (pp. 222-246). Cambridge, MA: Harvard University Press.

Gallagher, H. L., \& Frith, C. D. (2003). Functional imaging of "theory of mind". Trends in Cognitive Sciences, 7(2), 77-83. 
Gilbert, M. (1989). On social facts. London: Routledge.

Gilby, I. C. (2006). Meat sharing among the Gombe chimpanzees: harassment and reciprocal exchange. Animal Behaviour, 71, 953-963.

Goldberg, T. L., \& Wrangham, R. (1997). Genetic correlates of social behaviour in wild chimpanzees: evidence from mitochondrial DNA. Animal Behaviour, 54, 559-570.

Goodall, J. (1986). The chimpanzees of Gombe: patterns of behavior. Cambridge, MA: Belknap Press of Harvard University Press.

Gordon, A. D., Green, D. J., \& Richmond, B. G. (2008). Strong postcranial size dimorphism in Australopithecus afarensis: Results from two new resampling methods for multivariate data sets with missing data. American Journal of Physical Anthropology, 135(3), 311-328.

Greenfield, L. O. (1992). Origin of the human canine: A new solution to an old enigma. American Journal of Physical Anthropology, 35(S15), 153-185.

Gruber, T., Clay, Z., \& Zuberbühler, K. (2010). A comparison of bonobo and chimpanzee tool use: evidence for a female bias in the Pan lineage. Animal Behaviour, 80(6), 1023-1033.

Haile-Selassie, Y. (2001). Late Miocene hominids from the Middle Awash, Ethiopia. Nature, 412(6843), 178-181.

Haile-Selassie, Y., Suwa, G., \& White, T. D. (2004). Late Miocene Teeth from Middle Awash, Ethiopia, and Early Hominid Dental Evolution. Science, 303(5663), 15031505.

Hare, B., \& Kwetuenda, S. (2010). Bonobos voluntarily share their own food with others. Current Biology, 20(5), R230-R231.

Hare, B., Melis, A. P., Woods, V., Hastings, S., \& Wrangham, R. (2007). Tolerance Allows Bonobos to Outperform Chimpanzees on a Cooperative Task. Current Biology, 17(7), 619-623.

Hare, B., Plyusnina, I., Ignacio, N., Schepina, O., Stepika, A., Wrangham, R., \& Trut, L. (2005). Social cognitive evolution in captive foxes is a correlated by-product of experimental domestication. Current Biology, 15(3), 226-230.

Hare, B., \& Tomasello, M. (2005). Human-like social skills in dogs? Trends in Cognitive Sciences, 9(9), 439-444.

Hawkes, K. (2012). Stag Hunts or Rearing Environments? Current Anthropology, 53(6), 687688. 
Hawkes, K. (2014). Primate Sociality to Human Cooperation: Why Us and Not Them? Human Nature-an Interdisciplinary Biosocial Perspective, 25(1), 28-48.

Herrmann, E., Hare, B., Call, J., \& Tomasello, M. (2010). Differences in the Cognitive Skills of Bonobos and Chimpanzees. Plos One, 5(8).

Hirata, S., \& Fuwa, K. (2007). Chimpanzees (Pan troglodytes) learn to act with other individuals in a cooperative task. Primates, 48(1), 13-21.

Hobbes, T. (1668/1994). Leviathan: with selected variants from the Latin edition of 1668. In E. M. Curley (Ed.), (pp. lxxvii, 584 p.). Indianapolis: Hackett.

Ingmanson, E. J. (1996). Tool-using behavior in wild Pan paniscus: Social and ecological considerations. In A. E. Russon, K. A. Bard \& S. T. Parker (Eds.), Reaching into thought: the minds of the great apes (pp. 190-210). Cambridge: Cambridge University Press.

Jolly, C. J. (2001). A proper study for mankind: Analogies from the papionin monkeys and their implications for human evolution. Yearbook of Physical Anthropology, 44, 177204.

Joyce, R. (2006). The evolution of morality. Cambridge, MA: MIT Press.

Kanō, T. (1992). The last ape: pygmy chimpanzee behavior and ecology. Stanford: Stanford University Press.

Kitcher, P. (1998). Psychological Altruism, Evolutionary Origins, and Moral Rules. Philosophical Studies: An International Journal for Philosophy in the Analytic Tradition, 89(2/3), 283-316.

Kitcher, P. (2006). Biology and Ethics. In D. Copp (Ed.), The Oxford handbook of ethical theory (pp. 163-185). Oxford: Oxford University Press.

Kitcher, P. (2011). The ethical project. Cambridge, MA: Harvard University Press.

Korsgaard, C. M. (1993). The Reasons we can Share: An Attack on the Distinction between Agent-Relative and Agent-Neutral Values. Social Philosophy and Policy, 10(01), 2451.

Korsgaard, C. M. (2010). Reflections on the evolution of morality. The Amherst Lecture in Philosophy, 5, 1-29. Retrieved from http://www.amherstlecture.org/korsgaard2010/ website:

Lee, R. B., \& DeVore, I. (1969). Man the hunter. Chicago: Aldine Pub. Co.

Leigh, S. R., \& Shea, B. T. (1995). Ontogeny and the Evolution of Adult Body-Size Dimorphism in Apes. American Journal of Primatology, 36(1), 37-60. 
Leutenegger, W., \& Shell, B. (1987). Variability and Sexual Dimorphism in Canine Size of Australopithecus and Extant Hominoids. Journal of Human Evolution, 16(4), 359367.

Levis, N. A., \& Pfennig, D. W. (2016). Evaluating 'Plasticity-First' Evolution in Nature: Key Criteria and Empirical Approaches. Trends in Ecology \& Evolution, 31(7), 563-574.

Lewis, K. P., \& Barton, R. A. (2006). Amygdala size and hypothalamus size predict social play frequency in nonhuman primates: A comparative analysis using independent contrasts. Journal of Comparative Psychology, 120(1), 31-37.

Lovejoy, C. O. (2009). Reexamining Human Origins in Light of Ardipithecus ramidus. Science, 326(5949), 74, 74e71-74e 78.

Lovejoy, C. O., Latimer, B., Suwa, G., Asfaw, B., \& White, T. D. (2009). Combining Prehension and Propulsion: The Foot of Ardipithecus ramidus. Science, 326(5949), $72,72 \mathrm{e} 71-72 \mathrm{e} 78$.

McGrew, W. C. (1981). The female chimpanzee as a human evolutionary prototype. In F. Dahlberg (Ed.), Woman the gatherer. New Haven/London: Yale University Press.

McHenry, H. M. (1992). Body Size and Proportions in Early Hominids. American Journal of Physical Anthropology, 87(4), 407-431.

McPherron, S. P., Alemseged, Z., Marean, C. W., Wynn, J. G., Reed, D., Geraads, D., . . . Bearat, H. A. (2010). Evidence for stone-tool-assisted consumption of animal tissues before 3.39 million years ago at Dikika, Ethiopia. Nature, 466(7308), 857-860.

Meyer-Lindenberg, A., Buckholtz, J. W., Kolachana, B., Hariri, A. R., Pezawas, L., Blasi, G., ... Weinberger, D. R. (2006). Neural mechanisms of genetic risk for impulsivity and violence in humans. Proceedings of the National Academy of Sciences of the United States of America, 103(16), 6269-6274.

Miller, G. F. (2007). Sexual selection for moral virtues. Quarterly Review of Biology, 82(2), 97-125.

Moran, N. A. (1992). The Evolutionary Maintenance of Alternative Phenotypes. The American Naturalist, 139(5), 971-989.

Nietzsche, F. W. (1887/1967). On the genealogy of morals. In W. A. Kaufmann (Ed.), (pp. viii, 367 p.). New York: Vintage Books.

Nimchinsky, E. A., Gilissen, E., Allman, J. M., Perl, D. P., Erwin, J. M., \& Hof, P. R. (1999). A neuronal morphologic type unique to humans and great apes. Proceedings of the National Academy of Sciences of the United States of America, 96(9), 5268-5273. 
Palagi, E. (2006). Social play in bonobos (Pan paniscus) and chimpanzees (Pan troglodytes): Implications for natural social systems and interindividual relationships. American Journal of Physical Anthropology, 129(3), 418-426.

Perry, S., Baker, M., Fedigan, L., Gros-Louis, J., Jack, K., MacKinnon, K. C., . . Rose, L. (2003). Social conventions in wild white-faced capuchin monkeys - Evidence for traditions in a neotropical primate. Current Anthropology, 44(2), 241-268.

Pezawas, L., Meyer-Lindenberg, A., Drabant, E. M., Verchinski, B. A., Munoz, K. E., Kolachana, B. S., . . . Weinberger, D. R. (2005). 5-HTTLPR polymorphism impacts human cingulate-amygdala interactions: a genetic susceptibility mechanism for depression. Nature Neuroscience, 8(6), 828-834.

Pickering, T. R. (2013). Rough and tumble: aggression, hunting, and human evolution. Berkeley: University of California Press.

Pickford, M., \& Senut, B. (2001). The geological and faunal context of Late Miocene hominid remains from Lukeino, Kenya. Comptes Rendus de l'Académie des Sciences, 332(2), 145-152.

Pinker, S. (2011). The better angels of our nature: why violence has declined. New York: Viking.

Plavcan, J. M., \& van Schaik, C. P. (1992). Intrasexual Competition and Canine Dimorphism in Anthropoid Primates. American Journal of Physical Anthropology, 87(4), 461-477.

Plavcan, J. M., \& van Schaik, C. P. (1997). Interpreting hominid behavior on the basis of sexual dimorphism. Journal of Human Evolution, 32(4), 345-374.

Prüfer, K., Munch, K., Hellmann, I., Akagi, K., Miller, J. R., Walenz, B., . . . Paabo, S. (2012). The bonobo genome compared with the chimpanzee and human genomes. Nature, 486(7404), 527-531.

Rauss, K., \& Pourtois, G. (2013). What is Bottom-Up and What is Top-Down in Predictive Coding? Frontiers in Psychology, 4, 276.

Reno, P. L., McCollum, M. A., Meindl, R. S., \& Lovejoy, C. O. (2010). An enlarged postcranial sample confirms Australopithecus afarensis dimorphism was similar to modern humans. Philosophical Transactions of the Royal Society B-Biological Sciences, 365(1556), 3355-3363.

Reno, P. L., Meindl, R. S., McCollum, M. A., \& Lovejoy, C. O. (2003). Sexual dimorphism in Australopithecus afarensis was similar to that of modern humans. Proceedings of the National Academy of Sciences of the United States of America, 100(16), 94049409. 
Rilling, J. K., Scholz, J., Preuss, T. M., Glasser, M. F., Errangi, B. K., \& Behrens, T. E. (2011). Differences between chimpanzees and bonobos in neural systems supporting social cognition. Social Cognitive and Affective Neuroscience.

Rousseau, J.-J. (1755/1992). Discourse on the origin of inequality. In D. A. Cress (Ed.), (pp. xx, 92 p.). Indianapolis: Hackett Pub. Co.

Ruse, M. (1998). Taking Darwin seriously: a naturalistic approach to philosophy. Amherst, N.Y.: Prometheus Books.

Ruse, M., \& Wilson, E. O. (1986). Moral Philosophy as Applied Science. Philosophy, 61(236), 173-192.

Santillo, A. F., Englund, E., Medicinska, f., Neuropsykiatri, Clinical Memory Research, U., Oncology, K. L., . . Institutionen för kliniska vetenskaper, L. (2014). Greater loss of von Economo neurons than loss of layer II and III neurons in behavioral variant frontotemporal dementia. American journal of neurodegenerative disease, 3(2), 6471.

Santos, M., Uppal, N., Butti, C., Wicinski, B., Schmeidler, J., Giannakopoulos, P., . . Hof, P. R. (2011). von Economo neurons in autism: A stereologic study of the frontoinsular cortex in children. Brain Research, 1380, 206-217.

Saxe, R., \& Kanwisher, N. (2003). People thinking about thinking people: The role of the temporo-parietal junction in "theory of mind". Neuroimage, 19(4), 1835-1842.

Sayers, K., Raghanti, M. A., \& Lovejoy, C. O. (2012). Human Evolution and the Chimpanzee Referential Doctrine. Annual Review of Anthropology, 41, 119-138.

Schroepfer-Walker, K., Wobber, V., \& Hare, B. (2015). Experimental evidence that grooming and play are social currency in bonobos and chimpanzees. Behaviour, 152(3-4), 545-562.

Seeley, W. W., Carlin, D. A., Allman, J. M., Macedo, M. N., Bush, C., Miller, B. L., \& DeArmond, S. J. (2006). Early frontotemporal dementia targets neurons unique to apes and humans. Annals of Neurology, 60(6), 660-667.

Semendeferi, K., Armstrong, E., Schleicher, A., Zilles, K., \& Van Hoesen, G. W. (1998). Limbic frontal cortex in hominoids: A comparative study of area 13. American Journal of Physical Anthropology, 106(2), 129-155.

Sober, E., \& Wilson, D. S. (1998). Unto others: the evolution and psychology of unselfish behavior. Cambridge, MA/London: Harvard University Press.

Sterelny, K. (2012). Morality’s Dark Past. Analyse \& Kritik, 34(1), 95-115. 
Sterelny, K., \& Fraser, B. (unpublished). Evolution and moral realism. School of Philosophy. Australian National University. Unpublished manuscript.

Surbeck, M., Deschner, T., Schubert, G., Weltring, A., \& Hohmann, G. (2012). Mate competition, testosterone and intersexual relationships in bonobos, Pan paniscus. Animal Behaviour, 83(3), 659-669.

Surbeck, M., \& Hohmann, G. (2008). Primate hunting by bonobos at LuiKotale, Salonga National Park. Current Biology, 18(19), R906-R907.

Suwa, G., Kono, R. T., Simpson, S. W., Asfaw, B., Lovejoy, C. O., \& White, T. D. (2009). Paleobiological Implications of the Ardipithecus ramidus Dentition. Science, 326(5949), 69, 94-99.

Takemoto, H., Kawamoto, Y., \& Furuichi, T. (2015). How did bonobos come to range south of the congo river? Reconsideration of the divergence of Pan paniscus from other Pan populations. Evolutionary Anthropology, 24(5), 170-184.

Tan, J. Z., \& Hare, B. (2013). Bonobos Share with Strangers. Plos One, 8(1), e51922.

Tomasello, M. (2009). The question of chimpanzee culture, plus postscript (chimpanzee culture, 2009). In K. N. Laland \& B. G. Galef (Eds.), The Question of Animal Culture (pp. 198-221). Cambridge, MA: Harvard University Press.

Tomasello, M. (2014). A Natural History of Human Thinking. Cambridge, MA: Harvard University Press.

Tomasello, M. (2015). A natural history of human morality. Cambridge, MA: Harvard University Press.

Tomasello, M., Call, J., \& Hare, B. (2003). Chimpanzees understand psychological statesthe question is which ones and to what extent. Trends in Cognitive Sciences, 7(4), 153-156.

Tomasello, M., \& Carpenter, M. (2007). Shared intentionality. Developmental Science, 10(1), 121-125.

Tomasello, M., Melis, A. P., Tennie, C., Wyman, E., \& Herrmann, E. (2012). Two Key Steps in the Evolution of Human Cooperation: The Interdependence Hypothesis. Current Anthropology, 53(6), 673-692.

Ueno, A., \& Matsuzawa, T. (2004). Food transfer between chimpanzee mothers and their infants. Primates, 45(4), 231-239.

Van Arsdale, A. P., \& Wolpoff, M. H. (2013). A Single Lineage in Early Pleistocene Homo: Size Variation Continuity in Early Pleistocene Homo Crania from East Africa and Georgia. Evolution, 67(3), 841-850. 
Vervaecke, H., de Vries, H., \& van Elsacker, L. (2000). Dominance and its behavioral measures in a captive group of bonobos (Pan paniscus). International Journal of Primatology, 21(1), 47-68.

von Rohr, C. R., Burkart, J. M., \& van Schaik, C. P. (2011). Evolutionary precursors of social norms in chimpanzees: a new approach. Philosophy and Biology, 26(1), 1-30.

Waddington, C. H. (1953). Genetic Assimilation of an Acquired Character. Evolution, 7(2), 118-126.

Warneken, F., Chen, F., \& Tomasello, M. (2006). Cooperative activities in young children and chimpanzees. Child Development, 77(3), 640-663.

Warneken, F., Gräfenhain, M., \& Tomasello, M. (2012). Collaborative partner or social tool? New evidence for young children's understanding of joint intentions in collaborative activities. Developmental Science, 15(1), 54-61.

Warneken, F., Hare, B., Melis, A. P., Hanus, D., \& Tomasello, M. (2007). Spontaneous altruism by chimpanzees and young children. PLoS Biol, 5(7), e184.

Wellman, H. M., Lane, J. D., LaBounty, J., \& Olson, S. L. (2011). Observant, nonaggressive temperament predicts theory-of-mind development. Developmental Science, 14(2), 319-326.

West-Eberhard, M. J. (2003). Developmental plasticity and evolution. Oxford: Oxford University Press.

White, T. D., Asfaw, B., Beyene, Y., Haile-Selassie, Y., Lovejoy, C. O., Suwa, G., \& WoldeGabriel, G. (2009). Ardipithecus ramidus and the Paleobiology of Early Hominids. Science, 326(5949), 64, 75-86.

White, T. D., Lovejoy, C. O., Asfaw, B., Carlson, J. P., \& Suwa, G. (2015). Neither chimpanzee nor human, Ardipithecus reveals the surprising ancestry of both. Proceedings of the National Academy of Sciences of the United States of America, 112(16), 4877-4884.

White, T. D., Suwa, G., \& Asfaw, B. (1994). Australopithecus ramidus, a new species of early hominid from Aramis, Ethiopia. Nature, 371(6495), 306-312.

Wobber, V., Hare, B., Maboto, J., Lipson, S., Wrangham, R., \& Ellison, P. T. (2010). Differential changes in steroid hormones before competition in bonobos and chimpanzees. Proceedings of the National Academy of Sciences, 107(28), 1245712462.

Wrangham, R., \& Peterson, D. (1996). Demonic males: apes and the origins of human violence. Boston: Houghton Mifflin. 
Wrangham, R. W. (1993). The evolution of sexuality in chimpanzees and bonobos. Human Nature, 4(1), 47-79.

Yamamoto, S. (2015). Non-reciprocal but peaceful fruit sharing in wild bonobos in Wamba. Behaviour, 152(3-4), 335-357. 